\title{
Auditory Brainstem Encoding of Plosives in Korean Normal Hearing Listeners
}

\author{
Jihyeon Lee', Woojae Han² \\ ${ }^{1}$ Department of Speech Pathology and Audiology, Hallym University Graduate School, Chuncheon, Korea \\ ${ }^{2}$ Division of Speech Pathology and Audiology, Research Institute of Audiology and Speech Pathology, College of Natural Science, Hallym University, \\ Chuncheon, Korea
}

\begin{abstract}
Purpose: It is increasingly acknowledged that auditory brainstem response (ABR) elicited by speech can reflect the listener's perceptual cues of complex sound with replicability and reliability. This study sought to identify the brainstem responses evoked by Korean syllables and to characterize any relation between acoustic features of the speech and their neurophysiological responses at the brainstem level. Methods: Thirty young adults with normal hearing who were native Korean speakers participated in the study. As speech stimuli, nine Korean syllables, i.e., a combination of nine plosives $/ p, p^{*}, p^{h}, t, t^{*}, t^{h}, k, k^{*}, k^{h} /$ followed by an /a/ vowel naturally produced by a male speaker, were applied for electrophysiological measure. Each waveform of the syllable was analyzed by seven peaks, V, A, C, D, E, F, and $\mathrm{O}$, to determine latency, amplitude, and morphology. Results: According to transient responses, the peak $\mathrm{V}$-A latencies of alveolar syllables were significantly delayed, while supporting their long voice onset time. Latencies of peak C for /ta/ and /t*a/ syllables were prolonged, having longer consonant duration. Although the latencies of peak O usually looked prolonged for the aspirate syllables, they did not support acoustic characteristics in terms of the end of voicing. In the view of sustained responses, a significant difference exists in latency for the D-E and E-F inter-peaks. However, unlike the transient response, no relation between sustain features and brainstem response was found. Conclusion: Speech-evoked ABR reflects clear and synchronized patterns of the brainstem, while providing information on the transient response regarding auditory pathway encoding of the plosive consonant portion of speech. It can provide a fundamental and biological snapshot of auditory processing that predicts auditory-based communication skills and gain.
\end{abstract}

Key Words: Auditory brainstem response, Speech-evoked auditory brainstem response, Korean plosives, Transient responses, Sustained responses.

Received: February 28, 2017 / Revised: April 1, 2017 / Accepted: April 2, 2017

Correspondence: Woojae Han, Division of Speech Pathology and Audiology, Research Institute of Audiology and Speech Pathology, College of Natural Science, Hallym University, Hallimdaehak-gil 1, Chuncheon 24252, Korea

Tel: +82-33-248-2216 / Fax: +82-33-256-3420 / E-mail: woojaehan@hallym.ac.kr

\section{INTRODUCTION}

While generating the synchronous activity of neurons at the subcortical level, the auditory brainstem response (ABR) has been measured widely since the 1970s using only a small set of scalp electrodes (Hood, 1998; Jewett et al., 1970). With merits such as objective and passive recording, ABR is renowned as an attractive tool for clinical use to determine auditory thresholds and/or diagnose neuropathology with accuracy (Hood, 1998). Early studies of ABR mainly focused on the response evoked by simple stimuli such as click and tone burst (Hood, 1998; Jewett et al., 1970; Skoe \& Kraus, 2010). Although these simple stimuli have been useful in defining basic response patterns from the brainstem (Hood, 1998), they are limited in re- flecting various responses from complex sounds (e.g., speech and music to which we listen in everyday life) (Skoe \& Kraus, 2010). That is, they cannot imply unique characteristics of the complex sounds which consist of temporally and spectrally dynamic cues in their longer duration. As a result, the simple stimuli allow for an objective assessment of biological processes underlying the auditory function, but fail to evaluate comprehensive auditory processing and its related disorders at the brainstem level (Johnson et al., 2005; Sinha \& Basavaraj, 2010; Skoe \& Kraus, 2010).

In detail, the cues of complex sounds are instrumental in identifying which speech sounds are spoken (e.g., timing and harmonics) and who said them (e.g., pitch) (Johnson et al., 2005). The extent to which these pitch, timing, and harmonic 
cues are preserved in the response is linked to listeners' communication skills, such as speech perception in noise and reading/learning ability, and can be altered by active experience with sound (or simply auditory training) (Hornickel \& Kraus, 2012). In this regard, contemporary researchers have agreed that speech-evoked ABR enables clinicians to measure the listeners' perceptual cues not revealed by responses to the simple stimuli and is well suited for various clinical applications (Bellier et al., 2015; Rocha et al., 2010), while providing highly replicable and reliable responses (Russo et al., 2004). Although there is much potential in the clinical setting (Rocha et al., 2010; Skoe \& Kraus, 2010), speech-evoked ABR is still a young field (Sinha \& Basavaraj, 2010; Skoe \& Kraus, 2010). Since the early 1980s, when Greenberg first adopted a vowel for recording speechevoked ABR, more than 15 research papers have documented the response evoked by the /da/ syllable (Skoe \& Kraus, 2010), while applying different experimental procedures (Akhoun et al., 2008a), many languages (Akhoun et al., 2008b; Johnson et al., 2008), and populations across age (Friederici, 2005). The researchers who had studied the /da/ syllable insisted that it is a universal syllable and has a combination of transient and sustained features; also, its response is quite useful because it provides great perceptual challenges for the clinical population (Skoe \& Kraus, 2010). However, various kinds of speech stimuli exist. Furthermore, the Korean language differs in phonological characteristics and in speech sound acquisition and developmental patterns for the phonological processes despite similar orthographic mark (Han et al., 2013). Thus, the present study aimed to measure the brainstem responses evoked by several Korean plosives and to characterize the difference between acoustic features of naturally produced sounds and the neurophysiological responses at the brainstem level. The results will provide norm data and a standard of how normal hearing listeners perceive plosives having different acoustic features in the subcortical stage.

\section{MATERIALS AND METHODS}

\section{Participants}

Thirty young adults (18 female and 12 male) with normal hearing voluntarily participated in the study. Their ages ranged between 21 and 25 (mean: 23.70 years old). The participants reported a negative history of head and neck abnormalities, ear surgery, otologic disease, and head trauma. They also passed normal criteria at hearing screening to ensure A-type of tympanogram and sensitivity of $15 \mathrm{~dB}$ HL or better in each ear at 250 to $8,000 \mathrm{~Hz}$ and air-bone gaps no greater than $5 \mathrm{~dB}$ HL. All participants were right-handed and native Korean speakers and completed the informed consent form before the experimental procedure began.

\section{Stimuli}

The speech syllables were a combination of nine Korean consonants and an /a/ vowel, which were /pal, /p*a/, / $\mathrm{p}^{\mathrm{h}} \mathrm{a} /, / \mathrm{ta} /$, $/ \mathrm{t}^{*} \mathrm{a} /, / \mathrm{t}^{\mathrm{h}} \mathrm{a} /, / \mathrm{ka} /, / \mathrm{k}^{*} \mathrm{a} /$, and $/ \mathrm{kha} /$, and naturally recorded by a male speaker from the previous study (No \& Lee, 2012). Because speech-evoked ABR stimuli should have a low pitch with a fundamental frequency in the range of 80 to $300 \mathrm{~Hz}$ to better obtain sustain responses, we preferred to use stimuli produced by a male talker to a female talker (Skoe \& Kraus, 2010).

By a classification for the place of articulation, $/ \mathrm{p}, \mathrm{p}^{*}, \mathrm{p}^{\mathrm{h}} /$ are defined as bilabial stops that involve both lips as the articulator. $/ \mathrm{t}, \mathrm{t}^{*}, \mathrm{t}^{\mathrm{h}} /$ are alveolar stops articulated with the tongue against or close to the superior alveolar ridge, so named because it contains the alveoli of the superior teeth. Also, $/ \mathrm{k}, \mathrm{k}^{*}, \mathrm{k}^{\mathrm{h}} /$ are velar stops articulated with the back part of the tongue against the soft palate. On the other hand, for the classification of manner of articulation, these three groups also consist of lax, tense, and aspirate consonants. Lax /p, t, k/ consonants are produced with little aspiration of air, tense $/ \mathrm{p}^{*}, \mathrm{t}^{*}, \mathrm{k}^{*} /$ consonants are created by a tight glottal constriction, and aspirate $/ \mathrm{p}^{\mathrm{h}}, \mathrm{t}^{\mathrm{h}}, \mathrm{k}^{\mathrm{h}} /$ consonants need a strong puff of air or heavy aspi-ration. Among them, the tense consonants are especially considered as unique characteristics of the Korean language that are not found in most other languages (Kim et al., 2003).

Table 1 summarizes the acoustical analysis of nine plosives used in the current study: total syllable duration, pitch, F1, F2, F3, voice onset time (VOT), consonant duration, consonant intensity, vowel duration, and vowel intensity. The acoustic analysis followed the methods of a previous publication (Han et al., 2013) using the Praat acoustic system (Boersma \& Weenink, Univ. of Amsterdam, Amsterdam, the Netherlands).

\section{Electrophysiological test conditions}

In the recording parameter, the number of points was 1,024 and the maximum number among averages was 1,000. Epoch time was $85.33 \mathrm{msec}$. In the stimulus parameter, each plosive stimulus was fitted within $500 \mathrm{msec}$ in duration to correspond to the condition of custom stimulus type. Sampling frequency and sampling bit were adjusted to $48,000 \mathrm{~Hz}$ and 16 bit, respectively. While using alternating polarity, the stimulus intensity level and rate were $75 \mathrm{dBnHL}$ and 2,000 msec, respectively, and 
the insert delay was $0.8 \mathrm{msec}$. In addition, the responses were amplified with a gain of 100,000 and the evoked recordings were filtered from 100 to $3,000 \mathrm{~Hz}$. Artifacts were automatically rejected during the test if reached at $23.8 \mathrm{uV}$ or higher. Most of the ABR settings and procedures followed a tutorial paper of Skoe and Kraus (2010).

Two channel-electrodes were placed at $\mathrm{Fz}$ as a reference and at A1 (left) and A2 (right) as contralateral and ipsilateral, respectively (Bio-Logic Navigator Pro System; Bio-Logic System Corp., Mundelein, IL, USA). Stimuli were presented to the right ear by an inserted earphone. The test took approximately 1.5 hours to complete [1,000 presentations for each stimulus (at about $10 \mathrm{~min}$ ); thus, $10 \mathrm{~min} \times 9$ stimuli $=90 \mathrm{~min}$ per subject $]$.

\section{Data analysis}

Each waveform of the speech-evoked responses is marked as seven peaks, V, A, C, D, E, F, and $\mathrm{O}$, while providing major landmarks in the stimulus. Based on the tutorial paper [3], the $\mathrm{V}$-A complex is defined as the onset response. This sharp onset response arises from the broadband plosive burst for our study. Along with the $\mathrm{V}$-A peak, peaks $\mathrm{C}$ and $\mathrm{O}$ are considered transient responses because they match up with transient stimulus features (e.g., the beginning and the end of voicing, respectively). The region bounded by $\mathrm{D}$ and $\mathrm{F}$ forms the frequency following response. Peaks D, E, and F and small voltage fluctuations between peaks D and F may correspond to sustained stimulus features, namely, the fundamental frequency (F0) and its formants within the consonant-vowel formant transition. In addition, the D-E and E-F interpeak intervals occur at the period of the $\mathrm{F} 0$ of the stimulus.

Statistical analysis was performed using SPSS software (v. 20, IBM Co., Armonk, NY, USA). To see the main effect of latency and amplitude for speech stimuli, each factor was analyzed using a one-way analysis of variance (ANOVA) with repeated measure. If necessary, Scheffe post hoc was applied with multiple comparisons. The criterion used for the statistical significance was $p<0.05$.

\section{RESULTS}

All participants showed brainstem responses to the nine plosives. The grand average brainstem responses elicited by each plosive for a 5- and 60-msec stimulus duration are shown in Figures 1-3. By close observation, one can see a double-peak in two tense syllables $/ \mathrm{p}^{*} \mathrm{a} /$ and $/ \mathrm{t}^{*} \mathrm{a} /$.
Brainstem responses evoked by plosives and transient features

ANOVA showed a significant effect of latency for peak $\mathrm{V}[\mathrm{F}$ $(8,261)=168.804, p=0.000]$ and peak $\mathrm{A}[\mathrm{F}(8,261)=198.512$, $p=0.000]$. Scheffe post hoc comparison suggested that peak $\mathrm{V}$-A latencies of $/ \mathrm{ta} /, / \mathrm{t}^{*} \mathrm{a} /, / \mathrm{t}^{\mathrm{h}} \mathrm{a} /$, and $/ \mathrm{ka} /$ syllables were significant, appearing about 3 to $5 \mathrm{msec}$ later than the latencies of the other plosives ( $p=0.000)$. That is, the V-A complex, referred to as the onset response in the speech-evoked $A B R$, was very clear, and it also supported long VOT of the alveolar plosives, /ta/, $/ \mathrm{t}^{*} \mathrm{a} /, \mathrm{t}^{\mathrm{h}} \mathrm{a} /$ (Table 1$)$

Peak C and Peak O, namely, transient stimulus features (i.e., the beginning and end of voicing, respectively) showed a sig-
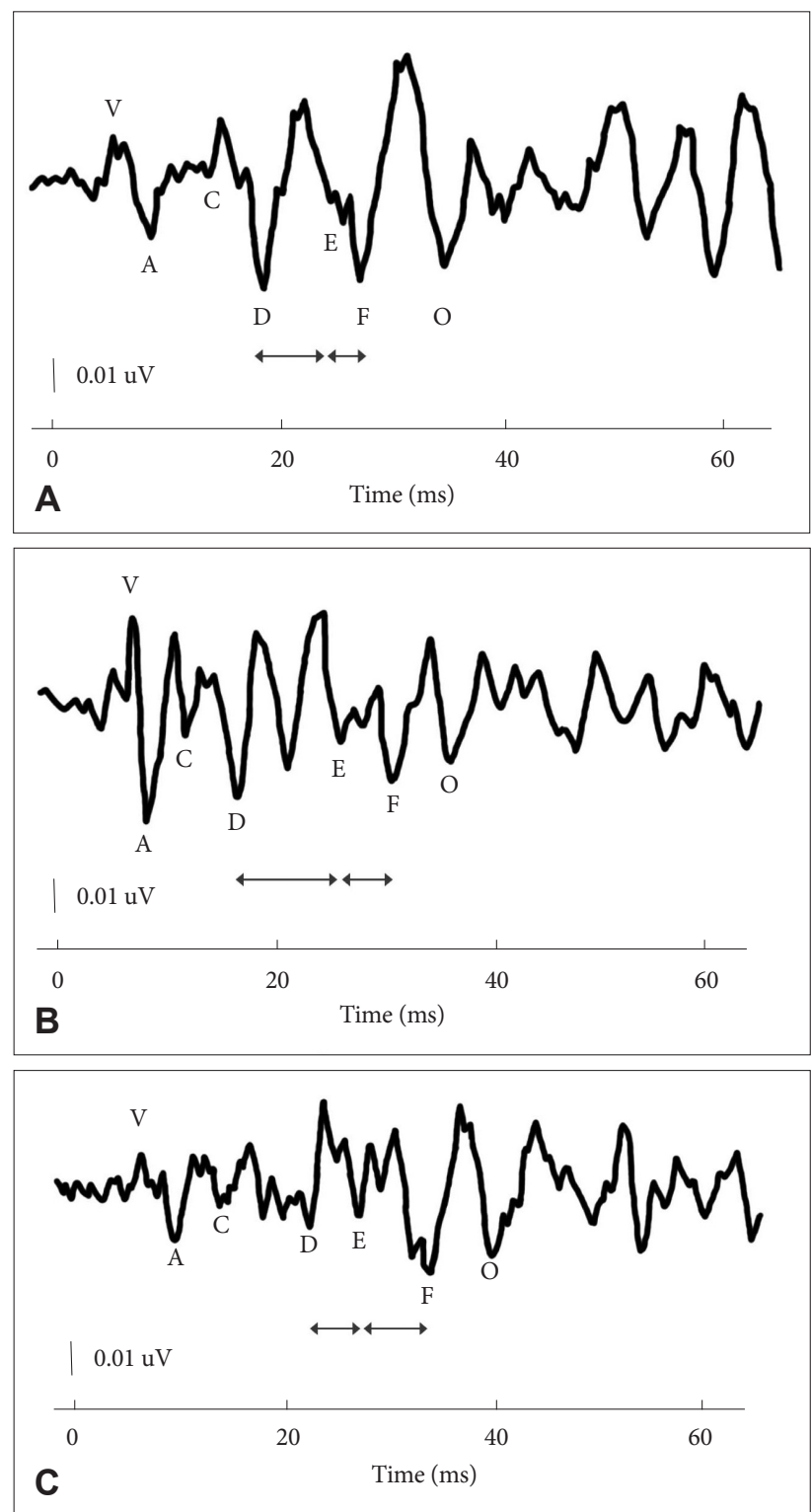

Figure 1. Transient and sustained features in the auditory brainstem response to bilabial /pa/ (A), / $\mathrm{p}^{\star} \mathrm{a} /(\mathrm{B})$, and $/ \mathrm{p}^{\mathrm{h}} \mathrm{a} /(\mathrm{C})$. 


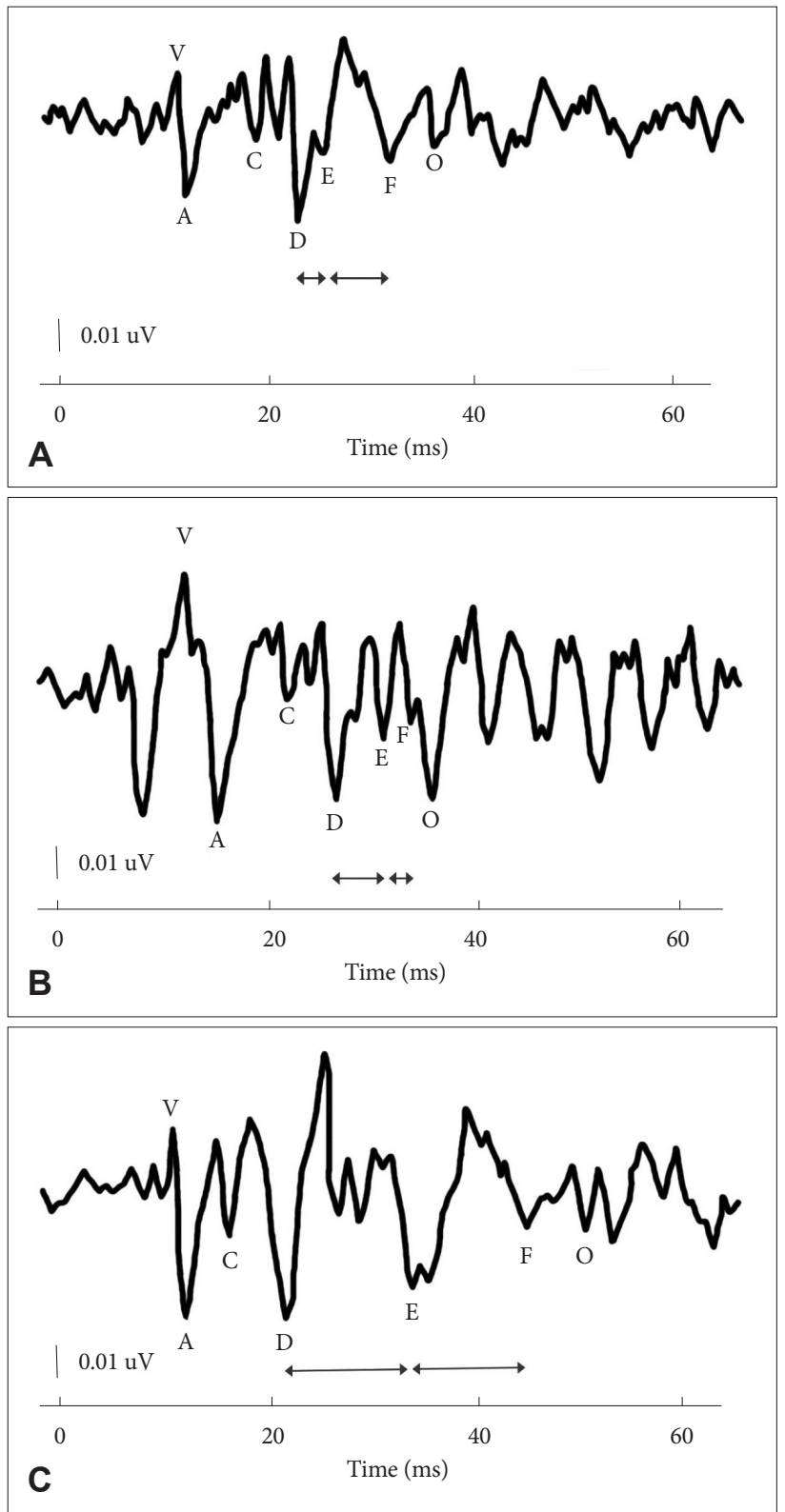

Figure 2. Transient and sustained features in the auditory brainstem response to alveolar /ta/ (A), / $/ t^{\star} a /(B)$, and $/ t^{\mathrm{h}} \mathrm{a} /(\mathrm{C})$.

nificant difference in the absolute latency among the nine plosives. The latency of peak $\mathrm{C}$ was significantly different across the plosives $[\mathrm{F}(8,261)=287.327, p=0.000]$. In detail, the post hoc comparison showed prolonged peak $\mathrm{C}$ latency in /ta/ and $/ t^{*} a /$ plosives $(p=0.000)$. This was quite similar to results from the acoustical analysis shown in Table 1, especially for longer consonant duration of two plosives. Although the latency of peak $\mathrm{O}$ was also significantly different across the stimuli $[\mathrm{F}(8$, $261)=891.029, p=0.000]$, the latency of only two velar $/ \mathrm{ka} /$ and $/ \mathrm{k}^{*} \mathrm{a} /$ plosives was significantly earlier than the others regardless of their vowel duration, which was analyzed in Table 1.
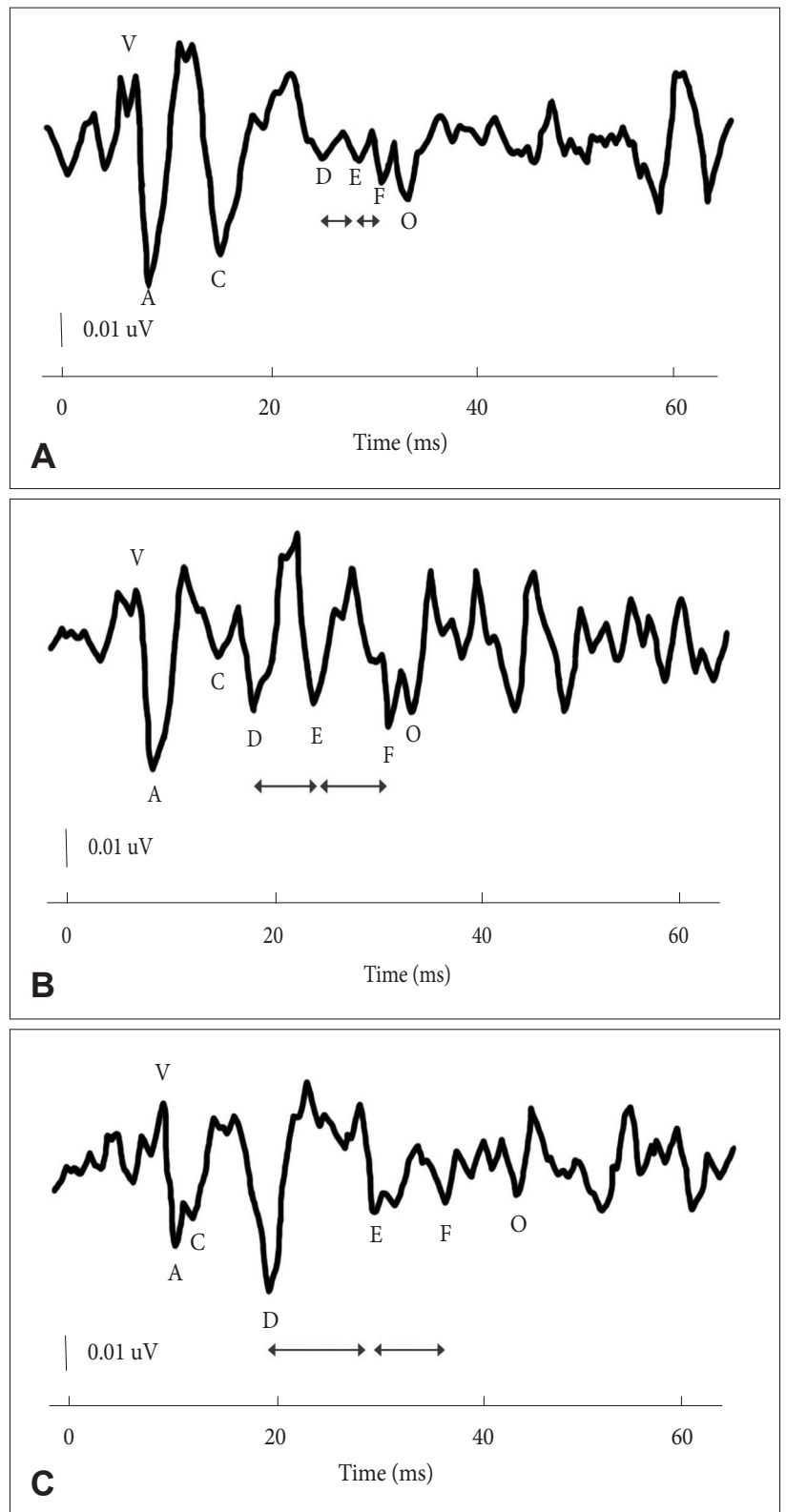

Figure 3. Transient and sustained features in the auditory brainstem response to velar $/ k a /(A), / k^{*} a /(B)$, and $/ k^{h} a /(C)$.

The mean and standard deviation for the latency of peaks V, A, C, D, E, F, and $\mathrm{O}$ for each plosive are documented in Table 2.

\section{Brainstem responses evoked by plosives and}

\section{sustained features}

Peaks D, E, and F are sustained stimulus features and are analogous to the F0 and its harmonics within consonant-vowel formant transition (Skoe \& Kraus, 2010). Latencies of the D-E and E-F interpeaks showed a significant difference among the plosives as $[\mathrm{F}(8,261)=312.765, p=0.000]$ and $[\mathrm{F}(8,261)=$ 107.941, $p=0.000$ ], respectively, in the one-way ANOVA. For 
Table 1. Summary of acoustical analysis for consonant-vowel stimuli used in the present study

\begin{tabular}{|c|c|c|c|c|c|c|c|c|c|}
\hline & \multicolumn{3}{|c|}{ Bilabial } & \multicolumn{3}{|c|}{ Alveolar } & \multicolumn{3}{|c|}{ Velar } \\
\hline & $/ \mathrm{pa} /$ & $/ \mathrm{p}^{*} \mathrm{a} /$ & $/ \mathrm{p}^{\mathrm{h}} \mathrm{a} /$ & $/ \mathrm{ta} /$ & $/ t^{*} a /$ & $/ \mathrm{t}^{\mathrm{h}} \mathrm{a} /$ & $/ \mathrm{ka} /$ & $/ \mathrm{k}^{*} \mathrm{a} /$ & $/ \mathrm{k}^{\mathrm{h}} \mathrm{a} /$ \\
\hline Total syllable duration $(\mathrm{msec})$ & 505 & 458 & 475 & 531 & 490 & 461 & 558 & 465 & 554 \\
\hline Pitch $(\mathrm{Hz})$ & 164 & 175 & 182 & 171 & 175 & 163 & 149 & 182 & 170 \\
\hline $\mathrm{F} 1(\mathrm{~Hz})$ & 994 & 941 & 1,013 & 1,011 & 1,009 & 1,175 & 826 & 800 & 1,014 \\
\hline $\mathrm{F} 2(\mathrm{~Hz})$ & 1,532 & 1,561 & 1,581 & 1,532 & 1,699 & 1,706 & 1,432 & 1,601 & 1,619 \\
\hline F3 $(\mathrm{Hz})$ & 2,656 & 2,576 & 2,623 & 2,650 & 2,651 & 2,735 & 2,547 & 2,582 & 2,654 \\
\hline VOT (msec) & 21 & 16 & 101 & 76 & 32 & 137 & 111 & 23 & 128 \\
\hline Consonant duration (msec) & 44 & 36 & 53 & 61 & 87 & 34 & 44 & 62 & 34 \\
\hline Consonant intensity $(\mathrm{dB})$ & 68.65 & 74.00 & 75.97 & 66.91 & 74.26 & 73.51 & 66.36 & 71.25 & 69.42 \\
\hline Vowel duration (msec) & 434 & 409 & 321 & 399 & 373 & 386 & 404 & 388 & 396 \\
\hline Vowel intensity $(\mathrm{dB})$ & 70.80 & 69.49 & 71.62 & 71.67 & 68.62 & 71.02 & 70.51 & 50.96 & 70.01 \\
\hline
\end{tabular}

VOT: voice onset time

Table 2. Mean $( \pm S D)$ of the latency of different peaks of speech evoked ABR

(unit: $\mathrm{msec}$ )

\begin{tabular}{|c|c|c|c|c|c|c|c|c|c|}
\hline \multirow{2}{*}{ Peaks } & \multicolumn{3}{|c|}{ Bilabial } & \multicolumn{3}{|c|}{ Alveolar } & \multicolumn{3}{|c|}{ Velar } \\
\hline & $/ \mathrm{pa} /$ & $/ \mathrm{p}^{*} \mathrm{a} /$ & $/ \mathrm{p}^{\mathrm{h}} \mathrm{a} /$ & $/ \mathrm{ta} /$ & $/ \mathrm{t}^{*} \mathrm{a} /$ & $/ \mathrm{t}^{\mathrm{h}} \mathrm{a} /$ & $/ \mathrm{ka} /$ & $/ \mathrm{k}^{*} \mathrm{a} /$ & $/ \mathrm{k}^{\mathrm{h}} \mathrm{a} /$ \\
\hline $\mathrm{V}$ & $7.01(1.42)$ & $7.46(0.54)$ & $7.39(1.4)$ & $11.57(0.89)$ & $12.89(1)$ & $11.19(0.81)$ & $12.85(1.47)$ & $7.32(0.76)$ & $9.32(0.63)$ \\
\hline A & $9.63(1.44)$ & $8.81(0.63)$ & $9.91(1.16)$ & $12.92(0.79)$ & $15.71(0.87)$ & $12.63(0.49)$ & $15.62(1.78)$ & $9.08(0.61)$ & $11.09(0.82)$ \\
\hline $\mathrm{C}$ & $16.79(0.67)$ & $16.65(0.89)$ & $14.71(0.96)$ & $18.78(0.56)$ & $22.16(0.74)$ & $16.8(0.89)$ & $20.17(0.98)$ & $15.38(0.67)$ & $15.28(0.76)$ \\
\hline $\mathrm{D}$ & $19.51(1.79)$ & $18.59(0.71)$ & $22.16(1.02)$ & $21.36(0.59)$ & $24.35(0.35)$ & $22.05(0.86)$ & $25.29(0.97)$ & $18.63(1.03)$ & $20.12(1.17)$ \\
\hline $\mathrm{E}$ & $27.84(1.13)$ & $25.91(0.71)$ & $27.14(0.81)$ & $23.38(0.68)$ & $26.69(0.4)$ & $35.31(1.19)$ & $28.72(0.61)$ & $24.23(0.91)$ & $30.05(0.99)$ \\
\hline $\mathrm{F}$ & $34.82(2.19)$ & $30.85(0.95)$ & $33.49(0.89)$ & $32.13(0.86)$ & $31.22(0.58)$ & $44.96(8.31)$ & $31.18(0.51)$ & $31.41(0.59)$ & $36.43(1)$ \\
\hline $\mathrm{O}$ & $40.02(1.4)$ & $36.24(0.71)$ & $39.55(0.88)$ & 36.21 (1.99) & $35.75(0.6)$ & $52.68(0.95)$ & $33.89(0.79)$ & $33.68(0.75)$ & $43.4(1.12)$ \\
\hline
\end{tabular}

ABR: auditory brainstem response

Table 3. Mean $( \pm S D)$ of the amplitude of different peaks of speech evoked ABR

(unit: $\mu \mathrm{V}$ )

\begin{tabular}{|c|c|c|c|c|c|c|c|c|c|}
\hline \multirow{2}{*}{ Peaks } & \multicolumn{3}{|c|}{ Bilabial } & \multicolumn{3}{|c|}{ Alveolar } & \multicolumn{3}{|c|}{ Velar } \\
\hline & $/ \mathrm{pa} /$ & $/ \mathrm{p}^{*} \mathrm{a} /$ & $/ \mathrm{p}^{\mathrm{h}} \mathrm{a} /$ & $/ \mathrm{ta} /$ & $/ \mathrm{t}^{*} \mathrm{a} /$ & $/ \mathrm{t}^{\mathrm{h}} \mathrm{a} /$ & $/ \mathrm{ka} /$ & $/ \mathrm{k}^{*} \mathrm{a} /$ & $/ \mathrm{k}^{\mathrm{h}} \mathrm{a} /$ \\
\hline $\mathrm{V}$ & $0.15(0.08)$ & $0.17(0.1)$ & $0.12(0.05)$ & $0.12(0.07)$ & $0.25(0.15)$ & $0.13(0.06)$ & $0.3(0.42)$ & $0.12(0.08)$ & $0.14(0.08)$ \\
\hline A & $-0.16(0.12)$ & $-0.19(0.08)$ & $-0.15(0.06)$ & $-0.15(0.07)$ & $-0.25(0.2)$ & $-0.23(0.11)$ & $-0.32(0.69)$ & $-0.21(0.07)$ & $-0.17(0.06)$ \\
\hline $\mathrm{C}$ & $-0.07(0.07)$ & $-0.23(0.25)$ & $-0.12(0.17)$ & $-0.08(0.14)$ & $-0.11(0.16)$ & $-0.14(0.1)$ & $5(0.41)$ & $-0.15(0.21)$ & $-0.1(0.24)$ \\
\hline $\mathrm{D}$ & $-0.2(0.11)$ & $-0.14(0.12)$ & $-0.15(0.13)$ & $-0.07(0.13)$ & $-0.04(0.13)$ & $-0.27(0.56)$ & $-0.09(0.11)$ & $-0.19(0.47)$ & $-0.24(0.37)$ \\
\hline $\mathrm{E}$ & $-0.2(0.12)$ & $-0.12(0.09)$ & $-0.1(0.14)$ & $-0.18(0.11)$ & $-0.2(0.09)$ & $-0.3(0.42)$ & $-0.08(0.09)$ & $-0.19(0.1)$ & $-0.16(0.13)$ \\
\hline $\mathrm{F}$ & $-0.23(0.17)$ & $-0.18(0.11)$ & $-0.2(0.09)$ & $-0.16(0.14)$ & $-0.12(0.11)$ & $-0.17(0.17)$ & $-0.1(0.07)$ & $-0.14(0.11)$ & $-0.12(0.11)$ \\
\hline $\mathrm{O}$ & $-0.18(0.14)$ & $-0.15(0.11)$ & $-0.17(0.13)$ & $-0.12(0.09)$ & $-0.22(0.16)$ & $-0.15(0.09)$ & $-0.12(0.13)$ & $-0.13(0.08)$ & $-0.1(0.07)$ \\
\hline
\end{tabular}

ABR: auditory brainstem response

the latency of the D-E interpeak, $/ \mathrm{p}^{*} \mathrm{a} /, / \mathrm{t}^{\mathrm{h}} \mathrm{a} /$, and $/ \mathrm{k}^{\mathrm{h}} \mathrm{a} / \mathrm{had}$ significantly longer intervals of 7.32, 13.26, and $9.93 \mathrm{msec}$, respectively $(p=0.000)$, whereas the latency of the E-F inter-peak for only the $/ \mathrm{ka} /$ plosive was significantly shorter $(2.45 \mathrm{msec})$ than the others $(p=0.000)$. However, no relation was found between the sustain features and latencies of D-E and E-F interpeaks for the natural stimuli used in this study. A significant difference in amplitude for the D-F interpeaks $[\mathrm{F}(8,261)=$ 227.821, $p=0.000$ ] can be explained in that D-E interpeak amplitude was much reduced in the $/ \mathrm{ka} /$ plosive, which had the lowest pitch and formants.
The amplitude of the V-A interpeak was usually larger in the tense plosives, which corresponded to high consonant intensity $[\mathrm{F}(8,261)=2.59, p=0.000]$. That is, three tense plosives, $/ \mathrm{p}^{*} \mathrm{a} /, / \mathrm{t}^{*} \mathrm{a} /$, and $/ \mathrm{k}^{*} \mathrm{a} /$, had $0.36,0.49$, and $0.32 \mu \mathrm{V}$ for the $\mathrm{V}-\mathrm{A}$ peak amplitude, but $/ \mathrm{ka} /$, which is a velar lax syllable, oddly, showed the highest V-A interpeak amplitude at $0.62 \mu \mathrm{V}$. The mean and standard deviation for the amplitude of the peaks $\mathrm{V}$, A, C, D, E, F, and O for each plosive is documented in Table 3. 


\section{DISCUSSIONS}

Speech-evoked ABR has a great advantage (Sinha \& Basavaraj, 2010). In particular, it provides a good temporal resolution for how behaviorally relevant speech sounds are processed in the brainstem (Skoe \& Kraus, 2010). The present study aimed to measure the brainstem responses evoked by nine Korean plosives and to characterize the differences between acoustic features of naturally produced syllables and their neurophysiological responses. The results displayed clear and distinguishable morphology from all plosives. They reflected the response from both transient and sustained segments which began with a plosive consonant, characterized by broadband frication, and followed by a harmonically rich and spectrally dynamic formant transition (Skoe \& Kraus, 2010). We confirmed that the morphology of speech-evoked ABR onset was dictated by the attack characteristics of the specific acoustic token (i.e., how quickly the sound reaches full volume). In particular, tense syllables exhibited a double-peak except for $/ \mathrm{k}^{*} \mathrm{a} /$. This might be because tense consonants showed somewhat higher intensity and longer duration when being produced (Kim et al., 2003), and their acoustic features were reflected well in the brainstem response. However, compared to $/ \mathrm{p}^{*}, \mathrm{t}^{*} /$ tense consonants, $/ \mathrm{k}^{*} /$ was not accurately reflected in the response due to velar stops articulated with the back part of the tongue against the soft palate (Kim et al., 2003). As mentioned in the previous study, transient responses, which are characterized by fast response peaks lasting fractions of milliseconds, may evoke the onset and offset of Korean syllables as in other languages (Hornickel \& Kraus, 2012; Johnson et al., 2005; Sinha \& Basavaraj, 2010; Skoe \& Kraus, 2010). For example, peak $\mathrm{V}$-A latencies of the alveolar plosives were significantly prolonged compared to bilabial and velar plosives in our study, although the velar plosive $/ \mathrm{k} /$ was exceptional. This is consistent with the acoustic feature of their longer VOT. Furthermore, when presenting alveolar plosives $/ \mathrm{t} /$ and $/ \mathrm{t}^{*} /$ with longer consonant duration, our subjects with normal hearing showed delayed latency for peak C. Along peak V-A, peak C (the beginning of voicing) can also reflect a transient feature as consonant duration (Skoe \& Kraus, 2010). To sum up, the current results of speech-evoked ABR support the previous findings of transient features (Johnson et al., 2005; Rocha et al., 2010; Sinha \& Basavaraj, 2010; Skoe \& Kraus, 2010).

On the other hand, the amplitude of peak V-A was much larger in tense plosives than in either lax or aspirate ones. This result is supported by a study of electrophysiological correlates of phonological processing in that within the classes of speech sounds, obstruent plosive consonants have sharper and larger stimulus onsets and produce more robust onset responses (Dehaene-Lambertz, 2000; Skoe \& Kraus, 2010). Sustained brain stem responses often called frequency following responses contain harmonically complex vowels. It is acknowledged that peaks D, E, and F were reflected those responses (Skoe \& Kraus, 2010). Interestingly, the amplitude of the D-F interpeak was much reduced in the $/ \mathrm{ka} /$ plosive of the current study. We might assume that its acoustic characteristics include low formant frequency and its formants. According to Johnson et al. (2005), the formant frequency differences distinguishing the stop consonants /b, d, g/ are represented by systematic and progressive latency differences in the speech-evoked ABR, with /ga/ responses occurring first, followed by /da/, and then by /ba/ (Johnson et al., 2008). This argument coincides with our results in that the latency of peak $\mathrm{D}$ was presented by /ka/, /ta/, and /pa/ successively.

The speech-evoked ABR can be used to assess specific impairments and enhancements in auditory processing because temporal and spectral characteristics of sounds are preserved in this subcortical response (Skoe \& Kraus, 2010). Notably, the subcortical auditory dynamically interacts with higher level cognitive processes to refine how speech sound is transcribed into neural code (Russo et al., 2004). Perhaps most crucially, this work has revealed that subcortical processing of speech is not hardwired (Dehaene-Lambertz et al., 2000; Skoe \& Kraus, 2010) and is instead malleable with experience and inextricably linked to cognitive functions involving the listener's language ability. This retuning of subcortical function likely involves the corticofugal pathway, an expansive tract of efferent connections that are even more abundant than afferent connections. Han et al. (2013), who measured the P1-N1-P2 complex using nine naturally produced Korean plosives, concluded that no significant difference existed in the cortical responses between Korean lax and tense syllables, which were significant for English phonology in terms of VOT. However, our ABR experiment found some correlation between VOT and brainstem responses. That is, the subcortical responses focus on the more acoustic feature of the stimuli than the cortical responses (Anderson et al., 2011; Dehaene-Lambertz et al., 2000).

Some limitations of the present study warrant further research. First, we need to consider talker dependence and/or characteristics due to using natural speech. Second, we need to show test-retest reliability of the speech-evoked ABR. Third, because the auditory brain stem plays an integral role in bin- 
aural processing, binaural interaction effects should be measured and discussed for the speech-evoked ABR. Despite these limitations, the results of the current study have various implications and potential for ABR as an objective and noninvasive tool for examining cognitive function and experience-dependent processes in sensory activity. The speech-evoked ABR has considerable utility in the study of populations where auditory function is of interest. Also, its results predict how well an individual can perceive speech in noisy backgrounds since background noise makes the neural response slower and smaller, but those who perceive speech in noise show less degradation (Anderson et al., 2011). Subcortical representation of the fundamental frequency, an important pitch cue, also predicts speech-in-noise perception in both children and older adults, with poor pitch representation corresponding to poor speechin-noise perception (Anderson et al., 2011; Johnson et al., 2005). In conclusion, the speech-evoked ABR may provide clinically valuable information for the assessment and remediation of auditory processing disorders and other auditorybased communication impairments. The observed reliabilities, particularly for clinically viable measures, recommend speechevoked ABR application for these purposes and as a biological index of training-related change. Overall, speech-evoked ABR can provide a fundamental and biological snapshot of auditory processing that predicts auditory-based communication skills and gain.

\section{Acknowledgments}

This work was supported by the Ministry of Education of the Republic of Korea and the National Research Foundation of Korea (NRF-2015 S1A3A2046760).

\section{REFERENCES}

Akhoun, I., Gallégo, S., Moulin, A., Ménard, M., Veuillet, E., Berger-Vachon, et al. (2008a). The temporal relationship between speech auditory brainstem responses and the acoustic pattern of the phoneme/ba/in normal-hearing adults. Clinical Neurophysiology, 119(4), 922-933.

Akhoun, I., Moulin, A., Jeanvoine, A., Ménard, M., Buret, F., Vollaire, C., et al. (2008b). Speech auditory brainstem response (speech ABR) characteristics depending on recording conditions, and hearing status: An experimental parametric study. Journal of Neuroscience Methods, 175 (2), 196-205.

Anderson, S., Parbery-Clark, A., Yi, H. G., \& Kraus, N. (2011). A neural basis of speech-in-noise perception in older adults. Ear and Hearing, 32(6), 750-757.

Bellier, L., Veuillet, E., Vesson, J. F., Bouchet, P., Caclin, A., \& Thai-Van, H. (2015). Speech auditory brainstem response through hearing aid stimulation. Hearing Research, 325, 49-54.

Dehaene-Lambertz, G., Dupoux, E., \& Gout, A. (2000). Electrophysiological correlates of phonological processing: A cross-linguistic study. Journal of Cognitive Neuroscience, 12(4), 635-647.

Friederici, A. D. (2005). Neurophysiological markers of early language acquisition: From syllables to sentences. Trends in Cognitive Sciences, 9(10), 481-488.

Han, W., Bahng, J., \& Park, J. (2013). The cortical evoked response elicited by nine plosives in normal hearing listeners. Korean Journal of Audiology, 17(3), 124-132.

Hood, L. J. (1998). Clinical Applications of the Auditory Brainstem Response. San Diego, CA: Singular Publishing Group.

Hornickel, J. \& Kraus, N. (2012). Breaking news: cABR can predict auditory-based communication skills. The Hearing Journal, 65(9), 28-30.

Jewett, D. L., Romano, M. N., \& Williston, J. S. (1970). Human auditory evoked potentials: Possible brain stem components detected on the scalp. Science, 167(3924), 1517-1518.

Johnson, K. L., Nicol, T. G., \& Kraus, N. (2005). Brain stem response to speech: A biological marker of auditory processing. Ear and Hearing, 26(5), 424-434.

Johnson, K. L., Nicol, T., Zecker, S. G., Bradlow, A. R., Skoe, E., \& Kraus, N. (2008). Brainstem encoding of voiced consonant-vowel stop syllables. Clinical Neurophysiology, 119(11), 2623-2635.

Kim, M. R. C., Lee, J., \& Lotto, A. J. (2003). An investigation of the manner contrast in inter-vocalic Korean stops. The Korean Language in America, 8, 75-84.

No, B. I. \& Lee, J. H. (2012). A comparison study of monosyllable recognition in listeners with sloping versus flat hearing loss types. Audiology, $8,78-86$

Rocha, C. N., Filippini, R., Moreira, R. R., Neves, I. F., \& Schochat, E. (2010). Brainstem auditory evoked potential with speech stimulus. Pró-Fono Revista de Atualização Científica, 22(4), 479-484.

Russo, N., Nicol, T., Musacchia, G., \& Kraus, N. (2004). Brainstem responses to speech syllables. Clinical Neurophysiology, 115(9), 20212030.

Sinha, S. K. \& Basavaraj, V. (2010). Speech evoked auditory brainstem responses: A new tool to study brainstem encoding of speech sounds. Indian Journal of Otolaryngology and Head and Neck Surgery, 62(4), 395-399.

Skoe, E. \& Kraus, N. (2010). Auditory brainstem response to complex sounds: A tutorial. Ear and Hearing, 31(3), 302-324. 